\title{
Pemodelan Regresi Cox Proportional Hazard Pada Data Perceraian
}

\author{
Haykal Abidin $^{1}$, Novita Eka Chandra ${ }^{2}$, Mohammad Syaiful Pradana ${ }^{3}$ \\ ${ }^{1}$ Universitas Islam Darul 'Ulum Lamongan, haykal1991abidin@gmail.com \\ ${ }^{2}$ Universitas Islam Darul 'Ulum Lamongan, novitaeka@ unisda.ac.id \\ ${ }^{3}$ Universitas Islam Darul 'Ulum Lamongan, syaifulp@unisda.ac.id
}

\begin{abstract}
The purpose of this research is modeling the Cox proportional hazard regression form on divorce data in Pelaihari sub-district, Tanah Laut district, South Kalimantan province. The source of the data comes from the Court Decision in Pelaihari District, Tanah Laut Regency, South Kalimantan. The data analysis technique uses software $\mathrm{R}$ with the steps, namely data description, Log-Rank test, checking proportional hazard assumptions, Cox regression model parameter estimation, backward selection with AIC, the best model parameter significance test, calculating Hazard ratio and interpretation of each predictor variable. Based on the results of the analysis and discussion, it was found that for the Log-Rank test, the variable survival time for domestic violence, forced marriage, lying and stories of disgrace differed significantly. While the model that meets the criteria after iteration up to 15 times is the 15 th model with the smallest AIC value and p-value $<0.05$ with factors that significantly influence divorce in Pelaihari sub-district based on modeling results using Cox proportional Hazard regression. are the variables of cheating, gambling, domestic violence, forced marriage, lies, jealousy and disgrace story variables.
\end{abstract}

Keywords: Divorcing, Pelaihari, Cox Proportional Hazard Regression

\begin{abstract}
Abstrak. Tujuan dari penelitian ini adalah memodelkan bentuk regresi Cox proportional Hazard pada data peceraian terjadi di kecamatan Pelaihari kabupaten Tanah Laut provinsi Kalimantan Selatan. Sumber data berasal dari data Putusan Pengadilan Kecamatan Pelaihari Kabupaten Tanah Laut Kalimantan Selatan. Teknik analisa data menggunakan software $R$ dengan langkah-langkahnya yaitu deskripsi data, uji Log-Rank, memeriksa asumsi proportional hazard, estimasi patrameter model regresi Cox, seleksi backward dengan AIC,uji signifikansi parameter model terbaik, menghitung Hazard ratio dan interpretasi masing masing variabel prediktor. Berdasarkan hasil analisis dan pembahasan diperoleh bahwa untuk uji Log-Rank adalah waktu survival variabel KDRT, kawin paksa, bohong dan cerita aib berbeda secara signifikan. Sedangkan model yang memenuhi kriteria setelah dilakukan iterasi hingga 15 kali adalah model ke 15 dengan memiliki nilai AIC terkecil dan nilai $p$-value $<0,05$ dengan faktor - faktor yang mempengaruhi secara signifikan terhadap perceraian di kecamatan Pelaihari berdasarkan hasil pemodelan menggunakan regresi Cox proportional Hazard adalah variabel selingkuh, perjudian, KDRT, kawin paksa, kebohongan, kecemburuan dan variabel cerita aib.
\end{abstract}

Kata Kunci : Perceraian, kecamatan Pelaihari, regresi Cox proportional Hazard 


\section{Pendahuluan}

Perceraian yang terjadi di kecamatan Pelaihari kabupaten Tanah Laut provinsi Kalimantan Selatan tahun 2017 mencapai 447 yang terdiri dari gugat cerai 351 dan cerai talak 96 (PPA Pelaihari,2017). Data tersebut mengindikasikan semakin tingginya kasus perceraian di kecamatan Pelaihari tahun 2017 dan memiliki dampak secara langsung pada anak.

Untuk mengatasi timbulnya sebuah perceraian dalam sebuah keluarga diperlukan sebuah analisis untuk mengidentifikasi faktor-faktor yang menyebabkan timbulnya perceraian. Salah satu alat yang digunakan untuk menganalisis faktor -faktor tersebut adalah satistika. Statistika merupakan suatu alat yang memegang peranan penting dalam pengambilan suatu keputusan, salah satunya adalah analisis data uji hidup. Analisis data uji hidup merupakan salah satu teknik statistika yang banyak digunakan dalam bidang kesehatan. Di dunia kesehatan analisis tersebut digunakan untuk mengetahui sifat karakteristik dari suatu penyakit. Di dalam analisis data uji hidup terdapat dua model salah satunya adalah model regresi Cox Proportional Hazard. Model Cox Proportional Hazard merupakan regresi survival, dengan respon yang berupa data waktu survival sampai suatu titik kejadian yang ditentukan.

Karakteristik utama model regresi Cox Proportional Hazard pada penelitian ini adalah data tersensor. Salah satu tipe data tersensor adalah tipe II. Data tersensor tipe II memiliki kelebihan yaitu lebih efisien waktu, karena percobaan akan dihentikan ketika telah mencapai $r$ kegagalan yang diinginkan, dengan ketentuan $1 \leq r \leq n$. Karakteristik analisis survival yang mengakomodasi adanya sensoring inilah yang membuat estimasi parameter pemodelan data survival dengan fungsi likelihood semakin komplek. Berdasarkan uraian tersebut, tujuan dari penelitian ini adalah memodelkan bentuk regresi Cox proportional Hazard pada data peceraian terjadi di kecamatan Pelaihari kabupaten Tanah Laut provinsi Kalimantan Selatan.

\section{Tinjauan Pustaka}

Perceraian merupakan suatu proses yang di dalamnya menyangkut banyak aspek seperti: emosi, ekonomi, sosial, dan pengakuan secara resmi oleh masyarakat melalui hukum yang berlaku layaknya sebuah perkawinan. Perceraian merupakan suatu reaksi terhadap hubungan pernikahan yang tidak berjalan dengan baik dan bukan merupakan suatu ketidaksetujuan terhadap lembaga perkawinan. Undang-undang nomor 1 tahun 1974 tentang Perkawinan menjelaskan faktorfaktor penyebab tersebut itu diantaranya [1]:

a. Salah satu pihak berbuat zina atau menjadi pemabuk, pecandu obat-obatan terlarang, penjudi dan lain-lain yang sulit untuk disembuhkan;

b. Salah satu pihak meninggalkan yang lainnya selama 2(dua) tahun berturutturut tanpa izin pihak yang lain dan tanpa alasan yang sah atau karena hal lain di luar kemauannya;

c. Salah satu pihak mendapat hukuman penjara 5(lima) tahun atau hukuman lebih berat setelah perkawinan berlangsung;

d. Salah satu pihak melakukan kekejaman atau penganiayaan berat yang membahayakan terhadap pihak lain. 
e. Salah satu pihak mendapat cacat badan atau penyakit yang mengakibatkan tidak dapat menjalankan kewajibannya sebagai suami/istri;

f. Antara suami dan istri terus menerus terjadi perselisihan dan pertengkaran dan tidak ada harapan akan hidup rukun lagi dalam rumah tangga

\section{Metode Penelitian}

\subsection{Uji Log-Rank}

Uji Log-Rank merupakan uji statistik non parametrik dan digunakan ketika data tidak simetris yaitu data miring ke kanan [2]. Berikut ini adalah hipotesis yang digunakan dalam pengujian Log-Rank.

$H_{0}$ : Tidak terdapat perbedaan pada kurva survival antara kelompok yangberbeda $H_{1}$ : Terdapat perbedaan pada kurva survival antara kelompok yang berbeda Statistik uji:

dengan

$$
X_{\text {hitung }}^{2}=\sum_{i=1}^{G} \frac{\left(o_{i}-E_{i}\right)^{2}}{E_{i}}
$$

Keterangan:

$$
\begin{aligned}
& o_{i}-E_{i}=\sum_{f=1}^{n} \sum_{f=1}^{G}\left(m_{i f}-e_{i f}\right) \\
& e_{i f}=\left(\frac{n_{i f}}{\sum_{i=1}^{G} n_{i f}}\right)\left(\sum_{i=1}^{G} m_{i f}\right)
\end{aligned}
$$

$o_{i}:$ nilai observasi individu kelompok ke- $i$

$E_{i}$ : nilai ekspektasi individu kelompok ke- $i$

$m_{i f}$ : jumlah objek yang mengalami event pada waktu ke- $t$ dan kelompok ke- $i$

$n_{i f}$ : jumlah objek yang masih bertahan pada waktu ke- $t$ dan kelompok ke- $i$

$e_{i f}$ : nilai ekspektasi pada waktu ke- $t$ dan kelompok ke- $i$

$\mathrm{n}$ : banyaknya observasi

$G$ : banyaknya kelompok

$f$ : failure event $(1,2, \ldots, h)$

$i: 1,2, \ldots, \mathrm{G}$

\subsection{Uji Asumsi Cox Proportional Hazard Dengan Goodness of Fit}

Cox PH dikatakan proportional jika hazard ratio variabel prediktornya konstan terhadap waktu. Jika terdapat variabel prediktor yang bergantung terhadap waktu maka asumsi proportional hazard tidak terpenuhi. Pengujian asumsi Cox $\mathrm{PH}$ dapat dilakukan dengan pengujian Goodness of Fit (GOF) dengan hipotesis sebagai berikut.

$\mathrm{H}_{0}$ : Asumsi $\mathrm{Cox} \mathrm{PH}$ terpenuhi

$H_{1}$ : Asumsi Cox $P H$ tidak terpenuhi

dengan daerah penolakan yang berlaku sebagai berikut:

1. Jika nilai $p$-value $<\alpha$, maka dinyatakan tolak $H_{0}$ atau variabel dinyatakan tidak memenuhi asumsi Cox PH.

2. Jika nilai $\chi_{\text {hitung }}^{2}>\chi_{\text {tabel }}^{2}$, maka dinyatakan tolak $H_{0}$ atau variabel dinyatakan tidak memenuhi asumsi Cox $P H$.

\subsection{Pengujian Parameter Dengan Uji Partial Likelihood Ratio}


Pengujian parameter bertujuan untuk memeriksa apakah variabel bebas mempunyai pengaruh yang nyata dalam model.pengujian Parameter pada model ini menggunakan uji partial likelihood ratio.

Uji Partial Likelihood Ratio dinotasikan dengan G. Statistik Uji ini mengikuti distribusi chi-square dengan derajat bebas $p$. Langkah-langkah dalam uji Partial Likelihood Ratio sebagai berikut [3].

a. Hipotesis

$H_{0}: \forall \beta_{j}=0, \mathrm{j}=1,2, \ldots ., p$ (variabel bebas tidak berpengaruh terhadap waktu survival)

$H_{1}: \exists \beta_{j} \neq 0, \mathrm{j}=1,2, \ldots ., p$ (variabel bebas berpengaruh terhadap waktu survival)

b. Taraf Signifikasi: $\alpha$

c. Statistik Uji: $G=-2\left[\operatorname{In} L(0)-\operatorname{In} L\left(\hat{\beta}_{j}\right)\right]$

Dengan:

In $L(0)$ merupakan log partial likelihood dari model tanpa variabel bebas (medel nol).

In $L\left(\hat{\beta}_{j}\right)$ merupakan log partial likelihood dari model yang terdiri dari $\mathrm{p}$ variabel bebas.

d. Kriteria keputusan: $H_{0}$ ditolak jika $G \geq X_{(\alpha, p)}^{2}$ atau $p$-value $\leq \alpha$

e. Kesimpulan:

Jika $H_{0}$ ditolak maka $\beta_{j} \neq 0$, yang artinya variabel bebas berpengaruh terhadap waktu survival (variabel dependen)

\subsection{Pemilihan Model Terbaik}

Pada penelitian ini, pemilihan model terbaik Cox dilakukan dengan menggunakan prosedur seleksi backward. Prosedur seleksi backward dihentikan apabila semua variabel yang masuk ke dalam model sudah signifikan. Untuk memeriksa setiap variabel yang akan dikeluarkan dilakukan sebuah pengujian. Langkah-langkah pengujian yang dilakukan dalam prosedur seleksi backward adalah sebagai berikut [4].

a. Hipotesis

$H_{0}: \forall x_{j}=0, j=1,2, \ldots ., p$ (variabel tidak berpengaruh terhadap model)

$H_{1}: \exists x_{j} \neq 0, j=1,2, \ldots, p$ (variabel berpengaruh terhadap model)

b. Taraf Signifikasi: $\alpha$

c. Statistik Uji: $\mathrm{z}^{2}=\left(\frac{\widehat{\beta}_{j}}{S E\left(\widehat{\beta}_{j}\right)}\right)^{2}$

d. Kriteria Keputusan: $H_{0}$ ditolak jika $z^{2} \geq X^{2}(\alpha, p)$ atau $p$-value $\leq \alpha$

e. Kesimpulan:

Jika $H_{0}$ ditolak maka $x_{j} \neq 0$, yang artinya variabel tersebut berpengaruh terhadap model, sehingga variabel tersebut tidak perlu dihapus dari model

\subsection{Model Regresi Cox Proporsional Hazard}

$$
\begin{aligned}
H(t, X) & =h_{0}(t) \exp \left(\beta_{0} X_{1}+\beta_{1} X_{1}+\ldots .+\beta_{k} X_{k}\right) \\
& =h_{0}(\mathrm{t}) e^{\left(\beta_{0} X_{1}+\beta_{1} X_{1}+\ldots .+\beta_{k} X_{k}\right)}
\end{aligned}
$$

dengan:

$h_{0}(\mathrm{t}) \quad$ : fungsi baseline hazard

$\beta_{1}, \beta_{2}, \ldots . \beta_{k} \quad$ : parameter regresi 
$X_{1}, X_{2}, \ldots . X_{k} \quad$ : variabel-variabel penjelas (kovariat)

\section{Hasil dan Pembahasan}

Kasus perceraian di kecamatan Pelaihari kabupaten Tanah Laut Kalimantan Selatan yang terdiri dari 462 sample dan 25 variabel independen (variabel bebas) yang mempengaruhi perceraian yaitu: perselingkuh $\left(x_{1}\right)$, mabuk-mabuk $\left(x_{2}\right)$, mengonsumsi sabu-sabu $\left(x_{3}\right)$, kebiasaaan berjudi $\left(x_{4}\right)$, meninggalkan $\left(x_{5}\right)$, hukuman penjara $\left(x_{6}\right)$, melakukan $\operatorname{KDRT}\left(x_{7}\right)$, cacat badan $\left(x_{8}\right)$, kawin paksa $\left(x_{9}\right)$, murtad $\left(x_{10}\right)$, nafkah $\left(x_{11}\right)$, ikut campur orangtua $\left(x_{12}\right)$, ucapan talak oleh pihak suami $\left(x_{13}\right)$, making love $\left(x_{14}\right)$, tuduhan palsu $\left(x_{15}\right)$, sering berbohong $\left(x_{16}\right)$, ancaman $\left(x_{17}\right)$, cemburu $\left(x_{18}\right)$, hutang $\left(x_{19}\right)$, malas bekerja $\left(x_{20}\right)$, menceritakan aib $\left(x_{21}\right)$, mandul $\left(x_{22}\right)$, mengusir $\left(x_{23}\right)$, boros $\left(x_{24}\right)$ dan kurang perhatian $\left(x_{25}\right)$. Dari hasil penelitian diperoleh bahwa faktor yang lebih dominan yang mengakibatkan perceraian adalah faktor perselisihan dan pertengakaran, meninggalkan pihak istri dan urusan nafkah. Waktu survival mulai timbulnya perkara hingga putusan pengadilan adalah 45 bulan 54 hari.

\subsection{Karakteristik Waktu Survival dan Uji Log-Rank Berdasarkan Faktor- Faktor yang Mempengaruhi Perceraian}

Untuk mengetahui apa benar tidak ada perbedaan yang berarti antara waktu survival dengan pihak yang bercerai yang timbul akibat faktor-faktor yang mempengaruhi perceraian, maka dilakukan uji Log-Rank. Uji Log-Rank merupakan uji statistik nonpaametrik dan sesuai digunakan ketika data tidak simetris yaitu data miring ke kanan. Selain itu uji Log-Rank banyak digunakan dalam uji klinis untuk melihat efisiensi dari suatu perawatan baru yang dibandingkan dengan perawatan yang lama apabila yang diukur adalah waktu hingga terjadi sebuah peristiwa. Uji Log-Rank digunakan untuk membandingkan Kaplan Meier dalam kelompok yang berbeda

Berikut ini adalah hipotesis yang digunakan dalam pengujian Log-Rank. $H_{0}$ : Tidak terdapat perbedaan pada kurva survival antara kelompok yang berbeda $H_{1}$ : Terdapat perbedaan pada kurva survival antara kelompok yang berbeda Berdasarkan uji Log-Rank diperoleh hasil pada Tabel 1 berikut.

Tabel 1. Hasil Uji Log-Rank Berdasarkan Faktor yang Mempengaruhi

\begin{tabular}{cc|cc|cc}
\hline variabel & $p$-value & variabel & $p$-value & variabel & $p$-value \\
\hline$x_{1}$ & 0,104 & $x_{10}$ & 0,966 & $x_{19}$ & 0,482 \\
$x_{2}$ & 0,3 & $x_{11}$ & 0,198 & $x_{20}$ & 0,679 \\
$x_{3}$ & 0,762 & $x_{12}$ & 0,966 & $x_{21}$ & 0,00769 \\
$x_{4}$ & 0,993 & $x_{13}$ & 0,435 & $x_{22}$ & 0,951 \\
$x_{5}$ & 0,507 & $x_{14}$ & 0,122 & $x_{23}$ & 0,524 \\
$x_{6}$ & 0,784 & $x_{15}$ & 0,839 & $x_{24}$ & 0,736 \\
$x_{7}$ & 0,00572 & $x_{16}$ & 0,0242 & $x_{25}$ & 0,87 \\
$x_{8}$ & 0,597 & $x_{17}$ & 0,616 & & \\
$x_{9}$ & 0,00953 & $x_{18}$ & 0,104 & & \\
\hline
\end{tabular}


Berdasarkan Tabel 1 hasil uji Log-Rank diperoleh waktu survival pihak yang bercerai berdasarkan variabel yang memiliki nilai $p$-value $<0,05$ (berbeda secara signifikan) adalah variabel KDRT $\left(x_{7}\right)$, variabel kawin paksa $\left(x_{9}\right)$, kebohongan $\left(x_{16}\right)$ dan cerita aib $\left(x_{21}\right)$. Sedangkan variabel yang nilai $p$-value $>0,05$ waktu survival pihak yang bercerai tidak berbeda secara signifikan.

\subsection{Pemodelan Regresi Cox Proportional Hazard Data Perceraian}

Pada bagian analisis survival ini akan dilakukan pemodelan data perceraian menggunakan regresi Cox Proportional Hazard. Langkah selanjutnya yaitu melakukan estimasi parameter, seleksi model terbaik, uji signifikansi parameter dan interpretasi model Cox Proportional Hazard berdasarkan model terbaik.

\subsubsection{Pengujian Asumsi Proportional Hazard dengan Goodness of Fit}

Untuk memperoleh hasil keputusan yang signifikan dari beberapa variabel yang mempengaruhi perceraian, maka pemeriksaan asumsi Proportional Hazard dilakukan dengan menggunakan metode Goodness of Fit. Pada pengujian asumsi Proportional Hazard, $H_{0}$ memiliki arti bahwa variabel yang diuji berpengaruh terhadap perceraian memenuhi asumsi Proportional Hazard dengan p-value > 0,05 . Sementara itu, $H_{1}$ memiliki arti bahwa variabel yang diuji tidak berpengaruh terhadap perceraian dengan nilai $p$-value $<0,05$. Hasil dari pengujian variabel yang diduga mempengaruhi perceraian ditunjukkan pada Tabel 2.

Dari hasil pengujian asumsi Cox Propotional Hazard dengan menggunakan metode Goodness of Fit yang disajikan pada Tabel 2 diperoleh variabel independen yang tidak memenuhi asumsi Cox Proportional Hazard adalah variabel pemakain obat terlarang/sabu-sabu $\left(x_{3}\right)$, hukuman penjara $\left(x_{6}\right)$, cacat badan $\left(x_{8}\right)$ dan variabel perhatian $\left(x_{25}\right)$. Nilai dari masing masing kedua variabel independen tersebut tidak memenuhi asumsi Cox Proportional Hazard ( $p$-value) $<0,05$ sehingga nilai $H_{1}$ di terima yang memiliki arti bahwa variabel independen yang diuji tidak memenuhi asumsi Proportional Hazard dengan $p$-value $<0,05$

Tabel 2. Hasil Pengujian Goodness $f$ Fit

\begin{tabular}{cc|cc|cc}
\hline Variabel & $p$-value & Variabel & $p$-value & Variabel & $p$-value \\
\hline$x_{1}$ & 0,74963 & $x_{110}$ & 0,31430 & $x_{20}$ & 0,51571 \\
$x_{2}$ & 0,27421 & $x_{111}$ & 0,45703 & $x_{21}$ & 0,48468 \\
$x_{3}$ & 0,03359 & $x_{12}$ & 0,73448 & $x_{22}$ & 0,43262 \\
$x_{4}$ & 0,42538 & $x_{13}$ & 0,67680 & $x_{23}$ & 0,31098 \\
$x_{5}$ & 0,29771 & $x_{14}$ & 0,19078 & $x_{24}$ & 0,36710 \\
$x_{6}$ & 0,04909 & $x_{15}$ & 0,35818 & $x_{25}$ & 0,00029 \\
$x_{7}$ & 0,13784 & $x_{16}$ & 0,74872 & & \\
$x_{8}$ & 0,02668 & $x_{17}$ & 0,25795 & & \\
$x_{9}$ & 0,74044 & $x_{18}$ & 0,46403 & & \\
$x_{10}$ & 0,31920 & $x_{19}$ & 0,32481 & & \\
\hline
\end{tabular}

\subsubsection{Estimasi Parameter Model Cox Proportional Hazard}

Setelah dilakukan pengujian asumsi, maka langkah selanjutnya adalah melakukan estimasi parameter model Cox Proportional Hazard. Untuk 
melakukan proses estimasi variabel yang digunakan adalah variabel independen yang memenuhi asumsi Cox Proportional Hazard. Variabel independen yang tidak memenuhi asumsi tidak digunakan. Tabel 3 berikut hasil estimasi parameter model Cox Proportional Hazard

Tabel 3. Estimasi Model Cox Proportional Hazard

\begin{tabular}{ccc|ccc}
\hline Variabel & $\begin{array}{l}\text { Estimasi } \\
\text { Parameter }\end{array}$ & $p$-value & Variabel & $\begin{array}{l}\text { Estimasi } \\
\text { Parameter }\end{array}$ & $p$-value \\
\hline$x_{1}$ & $-0,21329$ & 0,073 & $x_{14}$ & 0,34708 & 0,318 \\
$x_{2}$ & 0,05008 & 0,794 & $x_{15}$ & 0,23576 & 0,214 \\
$x_{4}$ & $-0,44766$ & 0,096 & $x_{16}$ & 0,58296 & 0,028 \\
$x_{5}$ & $-0,50177$ & 0,161 & $x_{17}$ & 0,09506 & 0,874 \\
$x_{7}$ & $-0,32904$ & 0,020 & $x_{18}$ & $-0,93260$ & 0,044 \\
$x_{9}$ & 0,98259 & 0,031 & $x_{19}$ & $-0,16857$ & 0,635 \\
$x_{10}$ & 0,04419 & 0,951 & $x_{20}$ & 0,15324 & 0,716 \\
$x_{110}$ & $-0,58141$ & 0,435 & $x_{21}$ & 1,51380 & 0,037 \\
$x_{111}$ & $-0,69305$ & 0,345 & $x_{22}$ & $-0,13918$ & 0,845 \\
$x_{12}$ & $-0,04015$ & 0,861 & $x_{23}$ & $-0,51792$ & 0,222 \\
$x_{13}$ & $-0,09049$ & 0,693 & $x_{24}$ & 0,38312 & 0,706 \\
\hline Likelihood Ratio=34,76, $D f=22, p$-value 0,04105 \\
\hline \multicolumn{5}{c}{}
\end{tabular}

Berdasarkan Tabel 3 setelah dilakukan uji serentak untuk mengetahui apakah variabel indepeden yang digunakan pada model berpengaruh signifikan atau tidak. Berdasarkan hasiil uji pada Tabel 3 diperoleh nilai $p$-value untuk Likelihood ratio test adalah 0,04105 ( $p-$ value $<0,05)$ sehingga diperoleh keputusan tolak $H_{0}$ yang artinya minimal ada 1 variabel independen yang berpengaruh terhadap model. Dengan demikian model Cox Proportional Hazard secara bersama sama telah berpengaruh secara signifikan dan berikut modelnya.

$$
\begin{aligned}
& h(t)=h_{0}(t) \exp \left(-0,21329 x_{1}+0,05008 x_{2}-0,44766 x_{4}-0,50177 x_{5}-\right. \\
& 0,32904 x_{7}+0,98259 x_{9}+0,04419 x_{10}-0,58141 x_{110}-0,69305 x_{111}- \\
& 0,04015 x_{12}-0,09049 x_{13}+0,34708 x_{14}+0,23576 x_{15}+0,58296 x_{16}+ \\
& 0,09506 x_{17}-0,93260 x_{18}-0,16857 x_{19}+0,15324 x_{20}+1,51380 x_{21}- \\
& \left.0,13918 x_{22}-0,51792 x_{23}+0,38312 x_{24}\right)
\end{aligned}
$$

Untuk mengetahui model diatas sudah tepat, maka dilakukan uji partial Likelihood ratio. Dari hasil output software $\mathrm{R}$, diperoleh nilai log likelihood untuk model Cox tanpa variabel bebas (model null) yaitu nilai In $L(0)=-2174,038$ dan nilai log likelihood untuk model Cox pada persamaan model sementara yaitu In $L\left(\hat{\beta}_{j}\right)=-2156,658$. Sehingga diperoleh $\mathrm{G}=-2\left[\operatorname{In} L(0)-\operatorname{In} L\left(\hat{\beta}_{j}\right)\right]=34,76$.

Karena $G=34,76 \geq \chi_{(\alpha, p)}^{2}(32,67056) . \quad$ dan $p$-value $<0,05$ sehingga $H_{0}$ ditolak hal ini dapat disimpulkan bahwa variabel dalam persamaan model sementara tersebut saling bepengaruh dalam model, mengindikasikan bahwa model tersebut lebih baik daripada model tanpa variabel bebas.

Selain itu juga, berdasarkan Tabel 3 masih terdapat beberapa variabel independen yang signifikan dengan memiliki nilai $p$-value $<0,05$ yaitu 
variabel $\operatorname{KDRT}\left(x_{7}\right)$, kawin paksa $\left(x_{9}\right)$, bohong $\left(x_{16}\right)$, cemburu $\left(x_{18}\right)$ dan cerita aib $\left(x_{21}\right)$. Sehingga menghasilkan keputusan tolak $H_{0}$ karena masih terdapat variabel yang belum signifikan maka dilakukan proses pemilihan model terbaik dengan cara eliminasi backward.

\subsubsection{Seleksi Model}

Pemilihan variabel yang masuk atau keluar dari model dapat dilakukkan dengan tiga cara yaitu seleksi forward, eleminasi backward dan prosedur stepwise. Pada penelitian ini menggunakan seksi backward, sehingga masingmasing tahapan akan diputuskan variabel mana yang merupakan prediktor terbaik untuk dimasukkan ke dalam model.

Tabel 4. Model Terbaik Sesuai KriteriaAIC

\begin{tabular}{cc|cc}
\hline Model & AIC & Model & AIC \\
\hline 1 & 4357,32 & 10 & 4339,28 \\
2 & 4354,67 & 11 & 4337,51 \\
3 & 4352,67 & 12 & 4336,78 \\
4 & 4350,7 & 13 & 4336,24 \\
5 & 4348,75 & 14 & 4335,4 \\
6 & 4346,81 & 15 & 4334,79 \\
7 & 4344,87 & & \\
8 & 4342,97 & & \\
9 & 4341,09 & & \\
\hline
\end{tabular}

Eliminasi backward dilakukan dengan cara membuang satu persatu variabel yang paling tidak signifikan. Variabel yang paling tidak signifikan adalah variabel yang memiliki $p$-value terbesar dalam uji parsial. Proses eliminasi akan berhenti hingga nilai Akaike's Information Criterion (AIC) terkecil dengan kriteria backward.

Pada Tabel 4 merupakan hasil estimasi parameter model Cox Proportional Hazard. Tabel 4 menunjukkan bahwa bahwa nilai AIC terkecil yaitu 4334,79 pada model ke 15. Perhitungan nilai AIC ini mengunakan metode eliminasi backward. Variabel yang terbentuk pada model 15 adalah variabel selingkuh $\left(x_{1}\right)$, judi $\left(x_{4}\right)$, KDRT $\left(x_{7}\right)$, kawin paksa $\left(x_{9}\right)$, berbohong $\left(x_{16}\right)$, cemburu $\left(x_{18}\right)$ dan variabel cerita aib $\left(x_{21}\right)$ yang mana variabel tersebut adalah faktor-faktor yang mempengaruhi perceraian di kecamatan pelaihari kabupaten Tanah laut kalimantan Selatan.

\subsubsection{Estimasi parameter Model Cox Proportional Hazard Terbaik}

Setelah diperoleh model terbaik, langkah selanjutnya adalah melakukan estimasi parameter untuk model terbaik. Berikut estimasi parameter model terbaik.

Tabel 5. Estimasi Parameter Model Cox Proportional Hazard

\begin{tabular}{cccc}
\hline Variabel & Koefisien & Standard error & $p$-value \\
\hline$x_{1}$ & $-0,1728$ & 0,1125 & 0,1244
\end{tabular}




\begin{tabular}{cccc}
$x_{4}$ & $-0,3956$ & 0,2143 & 0,0650 \\
$x_{7}$ & $-0,3129$ & 0,1336 & 0,0192 \\
$x_{9}$ & 1,0098 & 0,4544 & 0,0263 \\
$x_{16}$ & 0,6557 & 0,2528 & 0,0095 \\
$x_{18}$ & $-0,6488$ & 0,4197 & 0,1222 \\
$x_{21}$ & 1,6132 & 0,7172 & 0,0245 \\
\hline Likelihood ratio=27,28 $\mathrm{df}=7$ & p-value 0,0002962 & \\
\hline
\end{tabular}

Berdasarkan hasil estimasi parameter pada Tabel 5 diperoleh model Cox Proportional Hazard terbaik sebagai berikut.

$$
\begin{gathered}
h(t)=h_{0}(t) \exp \left(-0,1728 x_{1}-0,3956 x_{4}-0,3129 x_{7}+1,0098 x_{9}+\right. \\
\left.0,6557 x_{16}-0,6488 x_{18}+1,6132 x_{21}\right)
\end{gathered}
$$

Dari model Cox Proportional Hazard terbaik, dilakukan uji serentak untuk mengetahui apakah model telah signifikan atau belum. Uji serentak dilakukan dengan melihat nilai $p$-value Likelihood Ratio yaitu sebesar 0,2962 karena nilai $p$ value lebih kecil dari $\alpha(0,05)$ maka dapat diambil keputusan tolak $H_{0}$. Hal ini berarti minimal ada satu variabel yang signifikan dalam model Cox Proportional Hazard terbaik, sehingga model Cox Proportional Hazard terbaik telah signifikan.

\subsubsection{Interpretasi Model Cox Proportional Hazard}

Berdasarkan uji log partial likelihood dan pengujian asumsi Proportional Hazard disimpulkan bahwa model akhir Cox Proportional Hazard sebagai berikut

$$
\begin{gathered}
h(t)=h_{0}(t) \exp \left(-0,1728 x_{1}-0,3956 x_{4}-0,3129 x_{7}+1,0098 x_{9}\right. \\
\left.+0,6557 x_{16}-0,6488 x_{18}+1,6132 x_{21}\right)
\end{gathered}
$$

Persamaan tersebut menunjukkan tentang nilai exp $\left(\beta_{j}\right)$ menunjukan pengaruh variabel terikat terhadap fungsi hazard misalkan variabel tentang persoalan perselingkuhan dapat dinyatakan bahwa setiap bertambahnya persoalan perselingkuhan dalam rumah tangga maka semakin menambah besar risiko yang dimiliki oleh pasangan suami istri untuk mengalami perceraian berikut.nya, yaitu sebesar $e^{-0,1728}=1,1887$ maka bertambahnya persoalan perselingkuhan mengakibatkan risiko perceraian cukup besar yaitu $\mid(1,1887$ 1) $100 \% \mid=18,87 \%$

\section{Simpulan}

Hasil uji parsial pada pemodelan regresi Cox Proportional Hazard menunjukkan faktor yang signifikan berpengaruh terhadap kasus perceraian di kecamatan Pelaihari Kabupaten Tanah Laut propinsi kalimantan Selatan yang mempengaruhi model adalah variabel selingkuh $\left(x_{1}\right)$, judi $\left(x_{4}\right)$, KDRT $\left(x_{8}\right)$, kawin paksa $\left(x_{11}\right)$, berbohong $\left(x_{18}\right)$, cemburu $\left(x_{20}\right)$ dan cerita aib $\left(x_{23}\right)$ dengan model regresi Cox Proportional Hazard adalah sebagai berikut.

$$
\begin{gathered}
h(t)=h_{0}(t) \exp \left(-0,1728 x_{1}-0,3956 x_{4}-0,3129 x_{7}+1,0098 x_{9}\right. \\
\left.+0,6557 x_{16}-0,6488 x_{18}+1,6132 x_{21}\right)
\end{gathered}
$$

Hasil pemodelan regresi Cox Proportional Hazard berdasarkan faktor-faktor yang signifikan yang berpengaruh pada terjadinya perceraian di kecamatan Pelaihari kabupaten Tanah Laut propinsi Kalimantan Selatan menjelaskan bahwa untuk variabel selingkuh yang kita gunakan sebagai pemisalan dengan memiliki 
nilai Hazard ratio 1,1887. Nilai tersebut bermakna bahwa seseorang yang mengalami masalah dalam keluarga yang disebabkan oleh faktor selingkuh 1,1887 kali lebih besar rentan akan sebuah perceraian daripada seseorang yang tidak selingkuh.

\section{Daftar Pustaka}

[1] R. Indonesia, Peraturan pemerintah nomor 9 tahun 1975 tentang pelaksanaan Undang-undang nomor 1 tahun 1974 tentang perkawinan. Up. Indonesia, 1975.

[2] D. G. Kleinbaum and M. Klein, "Kaplan-Meier survival curves and the logrank test," in Survival analysis, Springer, 2012, pp. 55-96.

[3] D. W. Hosmer and S. Lemeshow, "MAY, S.(2008) Applied Survival Analysis: Regression Modeling of Time to Event Data." Hoboken, New Jersey: Wiley.

[4] D. Collett, Modelling survival data in medical research. CRC press, 2015. 